\title{
Práticas de Governança Eletrônica em Instituições Federais de Ensino Superior do Estado de Pernambuco
}

\author{
Electronic Governance Practices in Federal Higher Education Institutions in the State of \\ Pernambuco
}

\author{
Willyane Freire*1, Fabiola Lemos ${ }^{1}$, Taciana Barros ${ }^{2}$ \\ ${ }^{1}$ Secretaria Executiva, IFPE, Pernambuco, Brasil. \\ ${ }^{2}$ PROPAD, UFPE, Pernambuco, Brasil.
}

\begin{tabular}{l}
\hline I N F O A R T I G O \\
\hline Palavras-chave: \\
Governança Eletrônica, \\
Governo Eletrônico, \\
Educação.
\end{tabular}

$\overline{\text { A R T I C LE I N F O }}$

\section{Keywords:}

Electronic Governance,

Electronic Government

Education.

\begin{abstract}
RES U M O
O presente estudo buscou analisar a adequação dos websites das Instituições Federais de Ensino do Recife sob a ótica das práticas de governança eletrônica, conforme diretrizes de Mello e Slomski (2012). Para isso, tratouse de um estudo indutivo com abordagem qualitativa, cujos dados da pesquisa foram obtidos nos websites das Instituições de Ensino selecionadas, no período de maio de 2019. Com a formulação do IGEB, foi possível observar que as práticas de governança com melhor índice, de acordo com os dados que foram tratados, foi o da UFPE, dentre as três estudadas. Concluindo-se que o processo de adequação da governança eletrônica, nas Instituições públicas, ainda está em caráter de amadurecimento, ou seja, em contínuos processos de melhorias para a busca pelo fortalecimento no gerenciamento de informações, transparência e facilidade no acesso. Deste modo, considera-se relevante que a construção dos portais institucionais atenda às necessidades de governança eletrônica para melhoria e satisfação dos usuários.
\end{abstract}

A B S T R A C T
The present study sought to analyze the adequacy of the websites of the
Federal Education Institutions of Recife from the perspective of electronic
governance practices, according to guidelines by Mello and Slomski (2012).
For this, it was an inductive study with a qualitative approach, whose research
data were obtained on the websites of the selected Educational Institutions, in
the period of May 2019. With the formulation of the IGEB, it was possible to
observe that governance practices with the best index, according to the data
that was treated, was that of UFPE, among the three studied. In conclusion,
the process of adapting electronic governance in public institutions is still in
the process of maturing, that is, in continuous improvement processes in the
quest for strengthening information management, transparency and ease of
access. In this way, it is considered relevant that the construction of
institutional portals meet the needs of electronic governance for improvement
and user satisfaction.
and user satisfaction.

\footnotetext{
* Correspondência para autor:

freirewillyane@gmail.com (Willyane, F.) (ORCID: 0000-0003-3792-7419), famuska@gmail.com (Lemos, F.) (ORCID: 0000-0001-7117-310X), taciana.barros@gmail.com (Barros, T.) (ORCID: 0000-0003-1643-3030). 


\section{Introdução}

A agenda pública reformista da Constituição Federal de 1998 buscou tornar o setor público mais transparente na perspectiva de fortalecer o controle social na gestão pública (MACHADO et al, 2012). A busca pela democratização nos processos decisórios e do melhor acesso aos serviços públicos, assim como a escassez de recursos foram fatores que estimularam a busca por uma necessidade de estabelecimento de prioridades nos planos de ação para maior agilidade gerencial (FARAH, 2001).

Assim, com a transição de Administração Burocrática à Administração Pública Gerencial, os organismos públicos vêm buscando adequar suas estratégias, planos e diretrizes a uma gestão baseada em resultados (MACHADO et al, 2012) pautada no foco nos resultados ao cidadão e no diálogo "vivo" com suas necessidades.

Os cidadãos passaram a demandar melhores serviços do poder público em defesa dos seus direitos, assim como a buscar maiores informações acerca de suas necessidades. Daí decorre afirmar que a gestão pública passou a adotar metodologias para prestação de serviços qualificados e eficientes ao cidadão. Para isso, tais serviços buscaram estar alinhados com suas respectivas necessidades e permitindo um maior envolvimento da população na construção das ações governamentais, a partir de mecanismos de transparência e de controle social.

Com isso, as Instituições Públicas são desafiadas a adequar seus processos, procedimentos e serviços a essa nova realidade. Desse modo, as Tecnologias da Informação e Comunicação puderam melhorar a interatividade, a capacidade de intervenção e as relações entre a sociedade e o governo (SILVESTRE; ARAÚJO, 2013; PALUDO; PROCOPIUCK, 2014).

As relações entre governo e sociedade têm sido facilitadas por meio da governança eletrônica, pois essa consiste na habilidade e capacidade do governo de desenvolver a gestão de recursos e políticas públicas, de modo mais eficiente, responsável, transparente e democrático, promovendo mecanismos que permitam à sociedade participar do planejamento, das decisões e do controle em prol do bem comum (GARCIA, 2006; GRANJEIRO, 2012).

O governo eletrônico se compõe a partir da gestão eletrônica e dos serviços eletrônicos. Enquanto o processo gerencial se dá pela utilização das tecnologias na criação de repositórios de dados para os sistemas informacionais gerenciais os serviços eletrônicos é a utilização de serviços pela internet pelo cidadão on line (MELLO, 2009), sendo ambos adaptados às análises práticas de governança eletrônica nesse estudo. Tanto o processo gerencial quanto aos serviços eletrônicos são analisados neste estudo para formular um embasamento sobre o processo de governança eletrônica, já que as Instituições gerenciam quais informações e serviços serão lançados em suas plataformas online.

Assim, dada à relevância de adoção das práticas de governança eletrônica nas Instituições públicas de modo a auxiliá-las a cumprir suas respectivas missões e objetivos, este artigo se objetivou a analisar a adequação dos websites das Instituições Federais de Ensino do Recife sob a ótica das práticas de governança eletrônica, conforme as diretrizes de Mello e Slomski (2012).

\section{Governança Eletrônica: Premissas e Práticas}

\subsection{Governança na Gestão Pública}

A governança na Gestão Pública representa o desenvolvimento de mecanismos de controle, estratégias gerenciais e de liderança na perspectiva de avaliar, acompanhar, monitorar e dar diretrizes à construção de políticas públicas e à prestação de serviços condizentes com os interesses sociais. Desse modo, as Instituições públicas têm buscado se adequar aos cenários da Administração Pública Gerencial, cujos resultados são destinados às necessidades dos cidadãos e emanam deles a construção de políticas públicas (TCU, 2014; RUELAS; ARÁMBURO, 2006).

É sabido que uma adequada governança é estratégia de vantagem competitiva e facilitadora de um bom desenvolvimento econômico e social (STREIT; KLERING, 2004), com mecanismos de estímulo à transparência, de modo a minimizar os gastos com o erário e otimizando os recursos financeiros e materiais (RUELAS; ARÁMBURO, 2006). Outrossim, é importante mencionar que desenvolver estratégias que ampliem a eficiência, transparência, accountability potencializam a capacidade institucional dos governos locais, regionais e nacionais de atendimento às necessidades do público (MACHADO et al, 2012; RUELAS; ARÁMBURRO, 2006).

Para o Tribunal de Contas da União (2014), a boa governança no âmbito público requer o alinhamento entre a liderança, a estratégia e o controle. Na liderança, a condução de práticas que assegurem as condições mínimas 
para o desenvolvimento de uma boa governança. No que tange à estratégia, seriam as definições adequadas de diretrizes, objetivos, indicadores e metas entre o planejamento e a execução. O controle se relaciona à transparência, prestação de contas adequadamente e responsabilização.

Nesse estudo, por se tratar de uma abordagem no âmbito da governança eletrônica, abordar-se-ão a capacidade de resposta e o princípio da transparência por meio da prática de serviços que são ofertados, a saber, se no site consta a questão de mecanismo para queixa, denúncia pública, se disponibiliza informação sobre políticas públicas e se disponibiliza e-mails, telefones e endereços para solicitar informações. Enquanto que a confiabilidade pela capacidade de privacidade e segurança, ao observar, por exemplo se declara a política de privacidade em seu site ou garante que os dados informados não serão utilizados para outros fins, por exemplo.

Diante dessas diretrizes de governança na gestão pública e estando as Instituições, cada vez mais, inseridas no contexto da globalização e da Era do Conhecimento, o uso estratégico das tecnologias da informação e comunicação viabiliza a evolução desse novo modelo de gestão pública, uma vez que a internet tem se tornado frequente ferramenta para a disponibilização de informações de órgãos públicos, acesso a canais de relacionamento para dúvidas, reclamações e acompanhamentos, em especial, em seus sítios eletrônicos (RUELAS; ARÁMBURO, 2006).

\subsection{Governança Eletrônica}

Paul (2007, p. 177) ressalta que "a governança eletrônica requer diversos elementos da boa governança, tal como a transparência, accountability, participação, integração social, financiamento público, reforma e desenvolvimento gerencial".

Segundo Moura (2015), ter boas práticas de governança eletrônica está interligado à quantidade de prestação de informações que são evidenciadas, por meio do Governo Eletrônico, e para isso, faz-se necessária a análise da quantidade de informações disponibilizadas no website da respectiva Instituição.

A estrutura conceitual das práticas de governança eletrônica se divide, considerando a governança eletrônica, num sentido mais amplo, e abrange os conceitos de governo eletrônico, que foca nas tarefas gerenciais, e a democracia eletrônica que foca na interação cidadão - governo (FREY, 2002; RUEDIGER, 2002; HOLZER \& KIM, 2005; MELLO, 2009; MELLO \& SLOMSKI, 2010). Outrossim, ao se observar a governança eletrônica como subdividida em governo eletrônico e democracia eletrônica, afirma-se que esses se subdividem em cinco subgrupos de práticas de governança: conteúdo, serviços, participação cidadã, privacidade e segurança e usabilidade (MELLO, 2009; MELLO \& SLOMSKI, 2010; HOLZER E KIM (2005), conforme Figura 1.

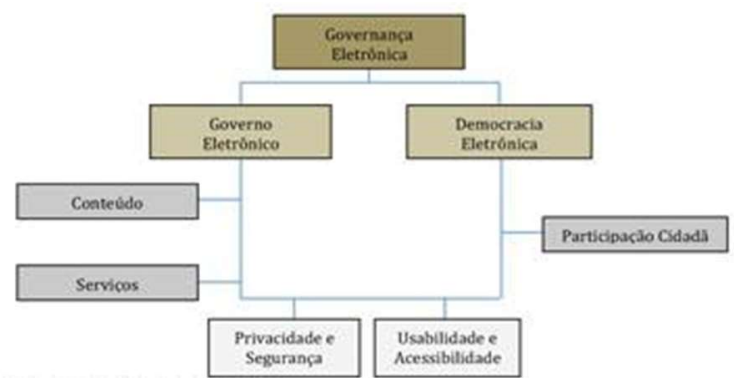

Figura 1 - Componentes da Governança Eletrônica.

Fonte: Mello e Slomski 2010, p.385.

No âmbito dos componentes da governança eletrônica, conforme figura acima, abordam-se, por exemplo, sites atualizados e a adequação das informações nos locais adequados. No caso, também se observa a questão de segurança e privacidade de informações e a oportunidade de participação do cidadão para interagir com a Instituição. Observa-se, por exemplo, a disponibilidade de uma estrutura que facilite a sua compreensão, contendo diretrizes que permitam acesso aos campos a serem preenchidos ou analisados de forma mais simples e direta (MELLO; SLOMSKI, 2012).

Os cinco subgrupos de práticas representam as variáveis que formaram o Índice de Governança Eletrônica dos Estados Brasileiros (IGEB). "O IGEB (2010) é um índice voltado para verificar o nível de implantação das práticas de governança eletrônica do poder executivo dos estados brasileiros” (MELLO; SLOMSKI, 2012, p. 199). 
Nesse estudo, foram adaptados à análise das práticas de governança desenvolvida pelas Instituições de Ensino Federais de Recife. Considerou-se, portanto, tantos as práticas de governo eletrônico, no que concerne ao conteúdo, serviços, privacidade e segurança, usabilidade e segurança, como as práticas apresentadas de participação cidadã.

O estudo das práticas de governança eletrônica foi utilizada pelos autores Varela et al (2010), por meio da análise das práticas de governança eletrônica dos municípios do estado de Santa Catarina, verificando sua correlação com as variáveis PIB (Produto Interno Bruto), IDH (Índice de Desenvolvimento Humano) e Tamanho. Os resultados apontados na pesquisa indicaram divergência entre o perfil dos municípios quanto à governança eletrônica, o que os autores sugerem como ponto necessário à formulação de políticas públicas para a promoção da transparência, na participação cidadã e na forma de prestar os serviços (Varela et al, 2010). Concluiu-se que os municípios maiores e com melhores condições socioeconômicas representadas pelo IDH, PIB aderiram a um maior número de práticas de governança eletrônica.

Outro trabalho que utiliza a governança eletrônica dos municípios do estado do Sergipe, baseado na proposta de Mello e Slomski, é Luft e Freitas (2014), que se propôs a apurar o índice de governança eletrônica relacionandoo ao tamanho da população dos municípios, consultando os portais eletrônicos das prefeituras, e se identificou como práticas mais relacionadas às de usuabilidade e acessibilidade em detrimento das de prestação de serviços e de participação cidadã. O estudo concluiu que os municípios cuja população é maior possui maiores índices. Varela et al (2011) também abordou as práticas de governança eletrônica dos municípios do estado de Santa Catarina correlacionando com as variáveis PIB (Produto Interno Bruto), IDH (Índice de Desenvolvimento Humano) e Tamanho, na perspectiva de compreender a gestão eletrônica e estimular as práticas de transparência e construção das políticas públicas com o olhar da sociedade.

\subsection{Governo Eletrônico}

Silva e Correa (2006, p. 3) citam que o governo eletrônico é um catalisador de uma mudança profunda nas estruturas governamentais, proporcionando boas práticas para decisão.

Ruelas e Arámburro (2006, p.3) ratificam que o governo eletrônico se "refere à otimização contínua dos serviços públicos, à participação da cidadania e governo mediante a transformação das relações internas e externas através da tecnologia e da internet”.

Segundo Dias (2006, p. 31), as oportunidades que podem surgir com o governo eletrônico são "criação de novos serviços, substituição de processos baseados em papel por processos eletrônicos, consolidação de processos e sistemas redundantes, maior participação da sociedade no governo, melhoria na infraestrutura informacional do país, dentre outros".

Para Garcia (2006, p.80-81), o governo eletrônico possui quatro perspectivas (Figura 2), conforme o estudo de Lenk e Traunmuller (2001):

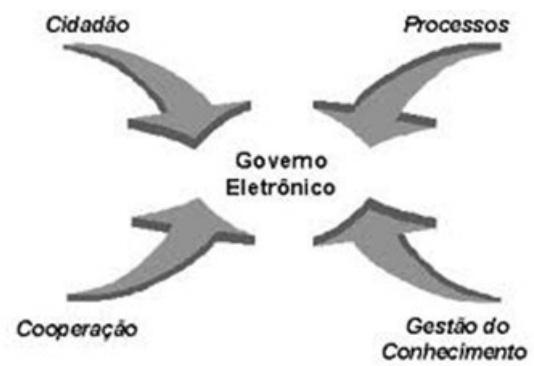

Figura 2 - Quatro perspectivas do governo eletrônico.

Fonte: Lenk e Traunmüller (2001) apud Garcia (2006, p.80).

Enquanto que a perspectiva cidadão apontada pelos autores orienta que o governo eletrônico deve considerar a oferta de serviços de utilidade pública ao cidadão a perspectiva de processos revela a necessidade de busca de uma adequação à implementação dos processos produtivos. Assim, compreende-se que, quando integradas as quatro perspectivas sob o olhar da necessidade do cidadão, da integração entre as instituições, da socialização das informações e da consolidação de processos e sua materialidade se convergem os fatores para o usufruto do governo eletrônico nos moldes das necessidades institucionais.

Concorda-se com Vaz (2008, p.1), ao relatar que com a implantação do governo eletrônico tem-se os processos redesenhados podendo "gerar além de maiores recursos e ampliação dos serviços, uma maior 
transparência que proporcionará maior integração e ao mesmo tempo maior possibilidade de acesso às decisões governamentais".

Dentre os estudos apontados acerca do Governo Eletrônico, o artigo, elaborado por Diniz et al (2009), abordao como um Programa de Governo Eletrônico trazendo um modelo de referência para análise da história do $e$-gov no Brasil, incorporando as etapas de desenvolvimento, atores e suas relações.

Vieira e Santos (2010) ressaltam, em seu estudo sobre o governo eletrônico e a busca por um governo mais democrático e transparente, na Escola de Gestão do Paraná, como uma importante ferramenta cujos desafios são resgatar a confiança dos cidadãos na gestão pública, capacidade para capacitar a sociedade para utilização das novas tecnologias, o incentivo da participação popular na gestão pública, uma vez que envolverá nas decisões governamentais, terá menos custo e maior agilidade e transparência.

Realizou um estudo por meio da análise de SWOT dos pontos fracos, fortes, as oportunidades e ameaças identificadas nos serviços de e-gov disponíveis nos estados de Santa Catarina, São Paulo, Paraná, Rio Grande do Sul e Minas Gerais. O estudo demonstrou que o fornecimento de serviços de governo eletrônico nos demais 21 estados da federação brasileira ainda é deficiente, necessitando de melhoria na qualidade de informação e interação com usuários e se observou que há a necessidade de um sistema de marketing por parte do governo para utilização dos ambientes para estimular o cidadão (DAMIN; SEGUNDO; MERLO, 2014).

\subsection{Boas Práticas da Governança Eletrônica}

Segundo Machado et al. (2012, p.188), a "governança é boa quando se atribui e gera recursos para responder aos problemas coletivos, em outras palavras, quando um Estado eficiente proporciona bens públicos de qualidade necessários aos seus cidadãos”. Sob a luz da Gestão da Qualidade, é visto como a busca pela satisfação do cliente se vem sendo a prioridade no processo da prestação de serviços e na fabricação de produtos, como mencionado por Carpinetti (2016).

O processo de identificação e da busca de melhorias estratégicas perpassam pela mensuração de dados adquiridos assim como pela avaliação de desempenho de acordo com índices compatíveis com o objetivo. "Medição de desempenho é, portanto, o processo de quantificar a eficiência elou eficácia das atividades de um negócio por meio de métricas ou indicadores de desempenho" (CARPINETTI, 2016, p.205).

Nesse contexto das boas práticas de governança eletrônica, pode-se ressaltar que o embasamento teórico foi o estudo realizado pelos autores Mello e Slomski (2012), modelo que é aderido por diferentes autores que realizaram estudos de governança eletrônica, tais como (FREY, 2002; RUEDIGER, 2002; HOLZER \& KIM, 2005; MELLO, 2009; MELLO \& SLOMSKI, 2010).

Utilizando-se de Mello e Slomski (2009), as práticas de governança eletrônica foram estudadas com o objetivo de apurar os índices de governança eletrônica que são utilizadas pelas capitais brasileiras (IGCB), em 2011, o que se identificou que Curitiba é a capital que possui maior pontuação das práticas de governança eletrônica, representando 58,98\% das práticas implantadas, e o Macapá possui uma menor pontuação, equivalente a $27,72 \%$. O estudo observou a média de práticas de governança eletrônica implantada nas capitais como de 40,59\%, necessitando-se ampliar a adesão ao governo eletrônico (SOUZA et al, 2013).

Porém, como este estudo caracterizou-se numa abordagem qualitativa, já que não foi mensurado estatisticamente e nem se utilizou de ferramentas de correlações para formular um parecer quantitativo. Foi reformulado, para atender ao objetivo deste artigo, utilizando-se do mesmo procedimento de avaliar às práticas de governança através dos questionários pré-definidos nestes estudos, e pontuado cada prática de cada sugbrupo de acordo com escala de referência conforme estudos de Eisenberg (2004); Holzer; Kim (2005); Mello (2009); Machado Et Al (2012).

\section{Procedimentos Metodológicos}

Segundo as bases lógicas da investigação, trata-se de um estudo indutivo que conduzem apenas a conclusões prováveis, cujo o objetivo dos argumentos é levar a conclusões do qual o conteúdo é mais amplo do que o das premissas nas quais se basearam, conforme Marconi e Lakatos (2010).

Quanto à abordagem do problema, tem-se uma abordagem qualitativa por estimular a análise, proporcionando ao pesquisador o desenvolvimento de conceitos e ideias a partir de padrões dos dados obtidos (OLIVEIRA, 2008). Esse método apresenta uma abordagem específica em relação aos dados coletados, onde a exploração dos fatos possibilita uma maior compreensão dos fenômenos investigados, permitindo que o pesquisador alcance o resultado almejado da pesquisa. 
Quanto aos objetivos o estudo, caracterizou-se como descritivo tendo seus objetivos bem definidos e a pesquisa adequadamente conduzida para descrever os dados identificados (NEUMAN, 1997).

Quanto aos procedimentos técnicos, tratou-se de uma pesquisa bibliográfica, cuja base teórica se deu pela investigação em livros, teses, dissertações e artigos científicos referentes aos principais temas de estudo (DUARTE; BARROS, 2010).

No que se refere ao tipo de amostragem, optou-se por uma amostragem não probabilística, uma vez que dependeu dos critérios estabelecidos pelo pesquisador, conforme orienta (GIL, 2011; MAROTTI et al., 2008). Considerando que se tratou de um estudo intencional, objetivou-se estudar as Instituições Federais de Ensino de Pernambuco, dentre as quais, o universo é composto por cinco Instituições, a saber, Universidade Federal de Pernambuco, a Universidade Rural de Pernambuco, o Instituto Federal de Pernambuco, a Universidade do Vale do São Francisco e o Instituto Federal do Sertão Pernambucano. Outrossim, o critério de seleção das escolhidas para análise foi abordar as que se localizavam na cidade do Recife pela sua proximidade geográfica, de modo que a nossa amostra foi composta por três delas.

A pesquisa foi construída com documentação direta, ou seja, os dados são coletados pelo pesquisador, utilizando-se de um formulário estruturado, de modo que os dados foram coletados em fontes públicas, facilmente acessíveis e com dados transparentes, permitindo a necessidade de captação, análise, relação das variáveis e interpretação- como foi feito (BEUREN, MOURA, KLOEPPEL, 2013).

Para analisar o nível de adesão às boas práticas de governança eletrônica, adotou-se as escalas apresentadas pelo referido Índice $(0$ - prática não identificada, 1 - existem algumas informações sobre a prática, 2 - a prática está implantada, mas de maneira incompleta e 3 - a prática está totalmente implantada). Escala essa que serviu para vários estudos de mesma natureza de aferição de índices como em Eisenberg (2004); Holzer; Kim (2005); Mello (2009); Machado Et Al (2012).

Dessa forma, foram realizadas consultas e análise dos websites das Instituições Federais de Ensino selecionadas como fonte de dados para o desenvolvimento do estudo, na perspectiva de identificar as práticas de governança eletrônica adotada, nesta pesquisa, que são as variáveis propostas por Mello e Slomski (2012), conforme subgrupos a seguir:

- Subgrupo "conteúdo": remete ao acesso a informações de contato, o acesso a documentos públicos e a deficiência de acesso, bem como o acesso a informações sensíveis de multimídia;

- Subgrupo "serviços": examina os serviços interativos, que permitem aos usuários comprar ou pagar por tais serviços, bem como capacidade dos usuários para aplicar ou registrar eventos ou serviços online;

- Subgrupo "participação cidadã”: analisa como o governo está envolvendo o cidadão e fornecendo mecanismos para participação dos cidadãos no governo online;

- subgrupo "privacidade e segurança": analisa a adoção de políticas de privacidade e questões relacionadas com as autenticações do website;

- subgrupo usabilidade e a acessibilidade: contempla as práticas relacionadas ao sistema como um todo, necessárias para o bom funcionamento das demais práticas.

Com o banco de dados formado pela coleta através da escala de referência, começa a delinear o desenvolvimento da formação do IGEB com os procedimentos a seguir, de acordo com a Tabela 1 .

Tabela 1 - Estabelecimento das pontuações para criação do IGEB.

\begin{tabular}{|c|c|c|c|c|c|c|}
\hline \multirow[b]{2}{*}{ Procedimentos } & \multicolumn{5}{|c|}{ Práticas } & \multirow[b]{2}{*}{ e Total } \\
\hline & Conteúdo & Serviços & $\begin{array}{l}\text { Participação } \\
\text { Cidadã }\end{array}$ & $\begin{array}{l}\text { Privacidade } \\
\text { Segurança }\end{array}$ & $\begin{array}{l}\text { Usabilidade } \\
\text { Acessibilidade }\end{array}$ & \\
\hline $\begin{array}{l}\text { Divisão dos pesos } \\
(\mathrm{x})\end{array}$ & 20 & 20 & 20 & 20 & 20 & 100 \\
\hline $\begin{array}{l}\text { Quantidade } \\
\text { práticas (y) }\end{array}$ & 12 & 15 & 10 & 8 & 19 & \\
\hline $\begin{array}{l}\text { Pontuação Máxima } \\
\text { de cada prática }(x / y)\end{array}$ & 1,667 & 1,333 & 2,000 & 2,500 & 1,053 & \\
\hline $\begin{array}{ll}\text { Pontuação para } \\
\text { resposta 0 }\end{array}$ & 0 & 0 & 0 & 0 & 0 & \\
\hline
\end{tabular}




\begin{tabular}{|lc|c|c|c|c|c|c|}
\hline $\begin{array}{l}\text { Pontuação } \\
\text { resposta 1 }\end{array}$ & para & 0,556 & 0,444 & 0,667 & 0,833 & 0,351 & \\
\hline $\begin{array}{l}\text { Pontuação } \\
\text { resposta 2 }\end{array}$ & para & 1,112 & 0,888 & 1,333 & 1,667 & 0,702 & \\
\hline $\begin{array}{l}\text { Pontuação } \\
\text { resposta 3 }\end{array}$ & para & 1,667 & 1,333 & 2,000 & 2,500 & 1,053 & \\
\hline
\end{tabular}

Fonte: Elaborada pelas autoras adaptado de (MELLO \& SLOMSKI, 2010; MELLO, 2009)

Foi estabelecido pesos iguais para cada subgrupo com escala de $0-100$, onde cada subgrupo recebeu peso 20 ou $20 \%$, dividindo 100 pelos 5 subgrupos, para poder obter a pontuação máxima para cada prática, já que a quantidade de práticas são diferentes para os subgrupos de acordo com os estudos de MELLO \& SLOMSKI, 2010; MELLO, 2009.

Então, foi dividido o peso de cada subgrupo pela quantidade de práticas analisadas, obtendo assim o valor máximo que cada resposta para poder pontuar. Com o ponto máximo, estabeleceram-se pontos para os outros pesos da escala de referência, sendo para a resposta " 3 " ao grupo de conteúdo o ponto 1,667, ao grupo de serviços 1,333, ao grupo de participação cidadã 2,000, ao grupo de privacidade e segurança 2,500, ao grupo de usabilidade e acessibilidade 1,053. Para a pontuação de resposta zero, foi atribuído para todos os grupos 0 ponto. Para a pontuação de resposta 1 , foi atribuído ponto 0,556 para conteúdo, 0,444 para serviços, 0,667 para participação cidadã, 0,833 para privacidade e segurança e 0,351 para usabilidade e acessibilidade. E, por fim, na pontuação de resposta 2 foi atribuído ponto 1,112 para conteúdo, 0,888 para serviço, 1,333 para participação cidadã, 1,667 para privacidade e segurança e 0,702 para usabilidade e acessibilidade.

Com as pontuações estabelecidas de acordo com cada ponto e subgrupo, alimentou-se a tabela com seus respectivos dados para o resultado do IGEB de cada Instituição de Ensino Superior Federal pesquisada. Isto posto, o estudo realizou-se com um desenho de multimétodos apresentados para a formulação final da análise.

\section{Resultados}

Os dados obtidos para realização deste estudo foram extraídos pelos sítios eletrônicos das Universidades Federal de Pernambuco (www.ufpe.br), da Universidade Rural de Pernambuco (www.ufrpe.br) e do Instituto Federal de Pernambuco (www.ifpe.edu.br), durante o mês de maio do corrente ano, tomando por base o modelo das práticas de governança eletrônica utilizado por Mello e Slomski (2012), cujos dados foram observados e analisados pelas próprias autoras do presente estudo, que, por sua vez, retiraram dos formulários duas questões por perceberem ser de áreas profissionais definidas que foram as Práticas de conteúdo 08 - Pcon 8 e Práticas de usabilidade e acessibilidade 01 - PUA 01.

É importante informar que este estudo foi feito com as análises das autoras que não possuem conhecimento técnico sobre aspectos de informática e isto torna o estudo com um olhar e percepções de usuários finais, de fato, como a facilidade de encontrar informações, a dinâmica de interfaces dos sites estudados, principalmente, na primeira página de cada, respectivamente. Observando também a complexidade dos usuários, tanto da comunidade acadêmica já integrada na Instituição quanto das pessoas com interesse à inserção nas mesmas e de toda a população que necessite de informações e dados de transparência.

Faz-se importante mencionar que o IGEB é projetado para mensurar a Governança Eletrônica dos estados brasileiros e, neste estudo, que se trata em Instituições Federais de Ensino Superior, foram feitas adaptações para analisar e responder os itens conforme a escala de referência. As questões em Práticas de serviço (Pser10, 11, 12, 13 e 14) foram referenciadas como práticas não identificadas, pois, as competências na análise da prestação de serviços são bastante pontuais com alguns órgãos estatais como departamentos de trânsito e questões jurídicas, de acordo com formulários apresentados no apêndice. As demais práticas foram analisadas e respondidas de acordo com as colocações dos formulários.

Isto posto, segue a apresentação do IGEB de cada Instituição de Ensino apresentada neste estudo.

Tabela 2 - Apresentação do IGEB das Instituições de Ensino.

$\begin{array}{lllllll} & \text { Pcon } & \text { Pser } & \text { PPC } & \text { PPS } & \text { PUA } & \text { IGEB } \\ \text { UFPE } & 13,338 & 11,107 & 10 & 10 & 15,093 & 59,538 \\ & & & & & & \\ \text { UFRPE } & 11,116 & 10,219 & 8,667 & 10 & 15,093 & 55,095 \\ \text { IFPE } & 13,896 & 11,552 & 10,667 & 10 & 12,285 & 58,\end{array}$


A priori, a análise será exposta de acordo com cada prática, individualmente, com o objetivo de perceber as tomadas de decisões no desenvolvimento dos sites de cada Instituição de Ensino.

\subsection{Prática de conteúdo}

A primeira a ser apresentada é a Prática de Conteúdo - Pcon - que teve doze itens em análise e versam, no geral, sobre a disponibilidade de dados, informações de contato, e acesso a documentos públicos oferecidos nos sítios eletrônicos.

A prática de conteúdo é significativa no que diz respeito à prática da governança eletrônica, uma vez que ela materializa a democratização do conhecimento e a disponibilidade para os diferentes públicos de informações, documentos, atividades organizacionais e o acesso a procedimentos e a facilidade na desburocratização de normas.

Os resultados materializados para o alcance do público, como por exemplo, resoluções de Conselho Superior, como documentos de estruturação dos setores, como os regulamentos de extensão, pesquisa e ensino. Além da disponibilização de documentos referentes ao planejamento e à prestação de contas institucional também são parte do arcabouço que compõe a prática de conteúdo em Instituições de Ensino Superior.

Conforme quadro 1.0, a Instituição IFPE obteve uma média de 13,896, seguida da UFPE com 13,338 e a UFRPE com 11,116. As questões que abordaram sobre autoria do desenvolvedor do site e a disponibilidade de agenda do gestor foram fatores que influenciaram na média das Instituições.

A prática de conteúdo teve maior predominância na Instituição de Ensino IFPE, demonstrando sua preocupação em fortalecer a governança eletrônica proporcionando maior acesso a informações e conhecimento sobre a Instituição, suas competências e seus documentos públicos.

Outrossim, infere-se que as Instituições necessitam de uma capacidade tecnológica para disponibilizar dados de interesse público e de relevância institucional.

A prática de conteúdo é parte da criação de repositórios de dados para os sistemas de informações gerenciais, o que significa dizer que obter essa prática ativa nas Instituições também requer uma reestruturação organizativa, uma desburocratização de normas e procedimentos, criação de modelos e uma capacidade de controle sobre as ações da gestão pública na perspectiva de ter dados que alimentem as informações de interesse dos cidadãos, demonstrando resultados alcançados e sua estrutura para o alcance deles (MACHADO et al, 2012) .

Afinal, conforme Moura (2015), ter boas práticas de governança eletrônica está relacionado à quantidade de prestação de informações evidenciadas no website de cada Instituição.

4.2 Prática de serviços

Nas práticas de Serviço, o IFPE obteve uma média de 11,552, já a UFPE 11,107 e o UFRPE 10,2019. Novamente, questões sobre a identificação do responsável pelo site para possíveis contatos fizeram diferença na análise.

A prática de serviços, conforme mencionado acima, teve como práticas não identificadas (Pser10, 11, 12, 13 e 14), uma vez que essas não se aplicavam à Instituição de ensino, objeto de abordagem deste estudo.

Essa prática é impulsionadora na busca pelo estímulo à otimização de recursos e no alcance do objetivo do cidadão com maior velocidade e menor tempo. Os serviços, quando acessíveis pelo portal eletrônico, facilita que a Instituição atenda às necessidades personalizadas da sociedade, porém com uma maior padronização e uniformidade.

Desse modo, pode-se inferir que a prática de serviços ela é um instrumento de fortalecimento da gestão eletrônica uma vez que promove instrumentos de controle social, de diálogo com a sociedade e de democratização do acesso às diferentes camadas sociais.

Todavia, a capacidade de governança eletrônica no que tange aos serviços também depende da capacidade dos seus usuários de acompanhar as mudanças de paradigmas, uma vez que nem todos os usuários possuem aptidões tecnológicas.

A prática de serviços, ao englobar disponibilização de mecanismos para submissão, monitoramento e queixas, tais como ouvidoria, é responsável por estimular a interação entre a Instituição e o público interessado. 


\subsection{Prática de Privacidade e Segurança}

O advento da tecnologia nas Instituições requereu a busca pela contínua segurança da informação e pela necessidade de se encontrar mecanismos de privacidade seja para preservar informações institucionais seja para preservar dados de servidores, estudantes e de partes interessadas.

Diante da segurança da informação, a prática de privacidade e segurança identificou nas Instituições a existência da política de privacidade no site institucional, permissão de revisão de dados apresentados nos sites, demonstração de acesso de limite de dados, informando que não será utilizado para outros fins senão aquele previsto e autorizado.

Nessa perspectiva, essa prática permite que o usuário que busca informações e serviços disponíveis no site busque uma garantia de que seus dados dispostos em formulários sejam destinados apenas para um determinado fim, que os dados estarão seguros de estarem disponíveis em possíveis situações de risco de invasão de sites e que também informações sigilosas poderão não ser expostas para pessoas e locais diversos.

Em Práticas de Privacidade e Segurança, com oito itens analisados, todas as Instituições de Ensino obtiveram média 10 neste subgrupo. Os tratamentos com privacidade e segurança foram observados.

\subsection{Práticas de Usabilidade e Acessibilidade}

No subgrupo de Práticas de Usabilidade e Acessibilidade, a UFPE obteve uma média de 15,093, seguido da UFRPE de 15,093 e do IFPE de 12,285. As questões de acesso em mais de um idioma, facilidade de acesso a portadores de necessidades especiais foram pontos chaves para análise deste grupo.

A padronização, o formato, o tamanho da homepage, as barras de navegações, as caraterizações dos dados postos como os links para informações sobre a Instituição foram alguns dos itens observados nessa prática.

A usabilidade e acessibilidade aborda o formato para utilização para os diferentes usuários interessados, dentre eles, aqueles com necessidades específicas, de forma que todos tenham a mesma experiência como um todo durante a navegação.

Pode-se inferir que essa prática é bastante necessária que seja observada, em especial, nas Instituições de Ensino, uma vez que estas têm buscado, cada vez mais, promover a inclusão social, de modo que as pessoas com necessidades específicas sejam inseridas em seus espaços acadêmicos.

Ao observar que as três Instituições estudadas está na busca, de forma equivalente, de adotar esta prática de governo eletrônico, pode-se inferir sua preocupação em assegurar melhores condições de acesso ao site.

\subsection{Participação Cidadã}

No subgrupo de Práticas de Participação Cidadã, o IFPE apresentou uma média de 10,667, a UFPE 10 e a UFRPE foi de 8,667. As questões sobre informações biográficas dos gestores foi o item que diferenciou as médias.

Essa prática de participação cidadã é a oportunidade de demonstrar a possibilidade de o cidadão interagir, controlar e se apropriar das ações, planos e objetivos organizacionais, de modo a contribuir considerando as suas respectivas realidades.

Essa prática fomenta o estímulo ao controle social no âmbito das Instituições de Ensino ao buscar nos sítios eletrônicos e-mails para contatos e detalhamento da política de retorno ao cidadão, a existência de boletim informativo online, disponibilidade de informações de gestores que compõem o quadro de pessoal da Instituição. Desse modo, observa-se, nessa prática, a composição de diretrizes que facilitam o diálogo entre o cidadão-usuário e a Instituição.

Somando-se as médias de todos os subgrupos obtivemos o IGEB das Instituições de Ensino: UFPE com 59,538, o IFPE com 58,4 e a UFRPE com 55,095, conforme tabela 2.

Como se observa a UFPE obteve melhor IGEB global apresentando um site com mais características de uma Governança Eletrônica praticada.

\section{Conclusões}

O governo eletrônico, no Brasil, ainda está em fase de amadurecimento das suas ações, pois a vinda da internet nos anos 90 de forma muito polarizada, onde os países desenvolvidos já utilizavam da tecnologia, fizeram nossos procedimentos demorarem para amadurecer e sem falar também no investimento governamental que se faz necessário para a implementação dos sistemas eletrônicos. Com o passar dos anos e o avanço tecnológico, a cada dia mais rápido, ficar de fora dos padrões de sistematização internacional fazem com que uma nação perca espaço 
competitivo, então moldar-se às novas conjecturas da informação é fator primordial. Nisto posto, o governo eletrônico possui muitas vantagens na sua usabilidade como explanado por (Chahin et al., 2004) que elencam alguns objetivos como: 1) melhoria da qualidade e inovação nos serviços prestados ao cidadão, 2) transparência e acesso à informação pela sociedade, 3) planejamento, avaliação e controle da ação governamental, com base nos resultados esperados, na elaboração de indicadores de desempenho e na identificação da clientela-alvo, entre outros.

Este estudo que teve como objetivo analisar a qualidade das práticas de Governança Eletrônica em Instituições Federais de Ensino Superior na perspectiva do IGEB (2010), donde foi adaptado às três Instituições de Ensino Superior Federal mais notórias do estado de Pernambuco, pontuando de acordo com a Escala de Referência de 0-3, também trabalhados em estudos de autores como (HOLZER; KIM, 2005; MELLO, 2009; MACHADO et al, 2012).

Após a aplicação e coleta dos dados, os achados da pesquisa indicaram que, dos cinco subgrupos, o que apresentou maior grau de adesão pelas Instituições de Ensino no tocante às práticas de governança eletrônica foi a Prática de Usabilidade e Acessibilidade, seguidos pelos subgrupos de Práticas de Conteúdo, Práticas de Serviço, Práticas de Privacidade e Segurança e Práticas de Participação Cidadã.

Obtendo como melhor IGEB a Universidade Federal de Pernambuco seguida do Instituto Federal de Pernambuco e posteriormente da Universidade Federal Rural de Pernambuco. É importante observar que as interfaces das Instituições estudadas apresentaram diferenças nas suas apresentações na primeira página dos Websites e quanto mais links e informações enxutas estiverem nesta página melhor será o acesso e exploração das informações pela população. Mesmo observando o IGEB como um método aferidor de Gestão de Cidades observou-se um alinhamento nas ações dos websites analisados, do qual se ver importante alinhamento nas intenções de melhorias da Governança Eletrônica.

Contudo, este estudo apresentou uma análise de simples aferição mas que as Instituições de Ensino abordadas possam ao decorrer do desenvolvimento eletrônico refazer novos índices para aferir e analisar a evolução dos tratos com a Governança Eletrônica.

\section{Referências}

Baptista, M. N.; Campos, D. C. C. (2013) Metodologias de pesquisa em ciências: análises quantitativa e qualitativa. [Reimp.]. - Rio de Janeiro: LTC.

Beuren, I. M., Moura, G.D. de, \& Kloeppel, N. R. (2013). Práticas de Governança Eletrônica e eficiência na utilização das receitas: uma análise nos estados brasileiros. Revista de Administração Pública (47), 2, 421441.

BRASIL. (2005) Lei no 12.527 de 18 de novembro de 2011.

BRASIL. (2017) Decreto 9.203, de 22 de novembro de 2017: Dispõe sobre a política de governança da administração pública federal direta, autárquica e fundacional.

Carpinetti, L. C. R.(2016). Gestão da Qualidade: Conceitos e Técnicas - $3^{\circ}$ ed. - São Paulo: Atlas.

Chahin, A.(2004) [et al]. E-GOV.BR - a próxima revolução brasileira: eficiência, qualidade e democracia: o governo eletrônico no Brasil e no mundo. São Paulo: Prentice Hale.

Damian, I.P.M., Segundo, J.E.S,; \& Merlo, E. M (2014). SWOT Analysus of the Services Provided by egovermment Sites in Brazil. Procedia Computer Science. 33 (0), 130-135. doi https://www.sciencedirect.com/science/article/pii/S1877050914008114?via\%3Dihub

Diniz, E. H. et al. (2009) O governo eletrônico no Brasil: perspectiva histórica a partir de um modelo estruturado de análise. Revista de Administração Pública, Rio de Janeiro, v. 43, n. 1, p. 23-48, jan./fev.

Duarte, J.B. A., Barros, A. (2010). Métodos e Técnicas de Pesquisa em Comunicação. 2 Ed., São Paulo: Atlas, $380 \mathrm{p}$.

Farah, M. F. S. (2001) Parcerias, novos arranjos institucionais e políticas públicas no nível local de governo. RAPRevista de Administração Publica, v.35, n.1, p.119-144, jan.fev.

Frey, K. (2000) Governança eletrônica: experiências de cidades europeias e algumas lições para países em desenvolvimento. Revista IP - Informática Pública, Belo Horizonte, v. 2, p. 31-48, maio.

Freitas, R. K. V.; Luft, M. C. M. S. (2014) Índice de Governança Eletrônica nos Municípios: Uma Análise do Estado de Sergipe.Revista Eletrônica de Ciência Administrativa, v. 13, n. 1, p. 56-73. 
Garcia, R.M. (2006) Governo eletrônico, informação e competência em informação. Inf.\& Soc.Est., v.16, n², p. 79-87, jul./dez.

Granjeiro, J. W. (2002) Administração Pública. 10 ed. Brasília: Vestcon.

Gil. A. C. (2011) Métodos e Técnicas de Pesquisa Social. 6 Ed., São Paulo: Atlas, 200p

Holzer, M.; Kim, S. (2005) Digital governance in municipalities worldwide (2005): a longitudinal assessment of municipal websites throughout the world. Division for Public Administration and Development Management. Department of Economic and Social Affairs, United Stations. Disponível em: http://unpan1.un.org/intradoc/groups/public/documents/ASPA/UNPAN022839.PDFaCESSO em 20 jan. 2015.

Machado, N.; Holanda, V. B. de; Ribeiro F., J.F.; Lopes, J.; Pederneiras, M. (2012) Gestão baseada em resultado no setor público. Uma abordagem didática para implementação em prefeituras, câmaras municipais, autarquias, fundações e unidades organizacionais. São Paulo: Atlas, 267p.

Marconi, M. A.; Lakatos, E. M. (2010) Fundamentos de metodologia científica. 7. ed. - São Paulo: Atlas.

Marotti, J; Galhardo, A.P.M; Furuyamma. R.J; Pigozzo, M.N; Campos, T.N.; Leganá, D.C., (2008) Amostragem em Pesquisa Clínica: tamanho da amostra. v. 20, n. 2, p. 186-194.

Mello, G.R. (2009) Estudo das práticas de governança eletrônica: instrumento de controladoria para a tomada de decisões na gestão dos estados brasileiros. Tese (Doutorado em Ciências Contábeis) - Programa de PósGraduação em Ciências Contábeis, Departamento de Contabilidade e Atuária, Faculdade de Economia, Administração e Contabilidade da Universidade de São Paulo, São Paulo.

Mello, G.R.; Slomski, V. (2012) Práticas de Governança Eletrônica: instrumentos de Controladoria para a tomada de decisão na Gestão Pública. IN MACHADO, N.; HOLANDA, V.B; FILHO, J.F.R.; PERDENEIRAS, M. (Org.). Gestão baseada em Resultados no Setor Público: uma Abordagem Didática para implementação em Prefeituras, Câmaras Municipais, Autarquias, Fundações e Unidades Organizacionais, São Paulo: Atlas, 267p.

Moura, G. D.; Dallabona, L. F.; Fank, O. L.; Almeida-Santos, P. S.; Varela, P. S. (2015) Análise das práticas de governança eletrônica de municípios do Estado de Santa Catarina. Ágora: revista de divulgação científica, v. 20, n. 2, p. 84-106.

Neuman, L. W. (1997). Social Research Methods: Qualitative and Quantitative Approaches. 3. ed. Boston: Allyn \& Bacon.

Oliveira, M. M. de. (2008) Como fazer projetos, relatórios, monografias, dissertações e teses. 4. ed. Rio de Janeiro: Elsevier.

Paul, S. A (2007) case study of E-governance initiatives in India. The International Information \& Library Review, v. 39, p. 176-184.

Paludo, A.M; Procopiuck, M. (2014) Planejamento Governamental: Referencial Teórico, conceitual e prático.2ed: São Paulo: Atlas, 226p.

Ruelas, A. L.; Arámburo, P. P. (2006) El gobierno electrónico: su estudio y perspectivas de desarrollo. UNI revista, v. 1, n. 3 , jul.

Ruediger, M. A. (2002). Governo eletrônico ou governança eletrônica-conceitos alternativos no uso das tecnologias de informação para o provimento de acesso cívico aos mecanismos de governo e da reforma do Estado. Anais do Congresso del CLAD, Caracas, Venezuela.

Silva, J. M.; Correa, P. S. A. (2006) Governança eletrônica e o empreendedorismo: uma análise dos sites das prefeituras do Estado do Paraná. In: ENCONTRO ANUAL DA ASSOCIAÇÃO NACIONAL DOS PROGRAMAS DE PÓS-GRADUAÇÃO EM ADMINISTRAÇÃO - ENANPAD, 2006, Salvador. Anais... Rio de Janeiro: ANPAD.

Streit, R. E., \& Klering, L. R. (2004). Governança pública sob a perspectiva dos sistemas complexos. In Encontro de administração pública e governança - EnAPG, 2004, Rio de Janeiro. Anais... Rio de Janeiro: EnAPG.

Silvestre, H. C.; Araújo, J. F. (Org.). (2013) Coletânea em Administração Pública. Lisboa: Escolar, 2013, 414p.

Souza, F. J. V. et al. (2013) Práticas de governança eletrônica: um estudo nos sítios das capitais brasileiras. Qualit@s Revista Eletrônica, v.14.n.2. 
TCU (Tribunal de Contas da União). (2014) Dez para a boa governança. Brasília: TCU, Secretaria de Planejamento, Governança e Gestão.

Vaz, J. C. (2008) Governo eletrônico e revisão de processos básicos da administração pública: superando o falso conflito entre eficiência e transparência. In: XIII Congresso Internacional del CLAD sobre la reforma Del estado y de la Administración Pública, Buenos Aires, nov.

Vieira, F.M. \& S., V.V.B. dos (2010). Governo Eletrônico: A Busca por um governo mais transparente e democrático. Anais... III Congresso Consad de Gestão Pública.

\section{APÊNDICE 1 - APRESENTAÇÃO DOS SUBGRUPOS PARA A ELABORAÇÃO DO IGEB}

\begin{tabular}{|l|l|}
\hline \multicolumn{1}{|c|}{$\mathbf{N}$} & \multicolumn{1}{c|}{ Práticas de conteúdo } \\
\hline PCon 1 & $\begin{array}{l}\text { disponibilizar uma lista de links de órgãos internos e externos, a localização dos escritórios, agências, setores } \\
\text { etc., contato com horário de funcionamento, endereço, nomes etc.; }\end{array}$ \\
\hline PCon 2 & disponibilizar agenda do gestor e das políticas da instituição; \\
\hline PCon 3 & disponibilizar os códigos e regulamentos do Estado; \\
\hline PCon 4 & $\begin{array}{l}\text { disponibilizar as informações do orçamento, relatórios contábeis, anexos da LRF, informações das licitações } \\
\text { em andamento, editais etc.; }\end{array}$ \\
\hline PCon 5 & disponibilizar informações sobre os cargos, competências e salários dos servidores; \\
\hline PCon 6 & disponibilizar as informações sobre concurso públicos, editais, gabaritos de provas, etc.; \\
\hline PCon 7 & permitir a cópia de documentos públicos, por meio de impressão, download etc.; \\
\hline PCon 9 & $\begin{array}{l}\text { disponibilizar informações sobre a gestão de emergências, utilizando o site como um mecanismo de alerta para } \\
\text { problemas naturais ou provocadas pelo homem; }\end{array}$ \\
\hline PCon 10 & publicar ofertas de empregos, de treinamento e de recursos encaminhamento de currículo pelo interessado; \\
\hline PCon 11 & disponibilizar um calendário de eventos da comunidade, um quadro de anúncios/informativos etc.; \\
\hline PCon 12 & $\begin{array}{l}\text { disponibilizar informações com atribuição de responsabilidade formal pelo conteúdo e pela atualização das } \\
\text { páginas; }\end{array}$ \\
\hline PCon 13 & disponibilizar em seu site os arquivos de áudio e vídeo de eventos públicos, palestras, encontros etc. \\
\hline
\end{tabular}

\begin{tabular}{|l|l|}
\hline \multicolumn{1}{|c|}{$\mathbf{N}$} & \multicolumn{1}{c|}{ Práticas de serviço } \\
\hline PSer1 & disponibilizar e-mails, telefones e endereços para solicitar informações; \\
\hline PSer 2 & a página principal deve ser personalizada para facilitar o acesso do cidadão aos serviços; \\
\hline PSer3 & $\begin{array}{l}\text { Permitir o acesso a informações privadas utilizando senhas, como em registros criminais, educacionais, } \\
\text { médicos, cadastro civil etc.; }\end{array}$ \\
\hline PSer4 & $\begin{array}{l}\text { Permitir o acesso a informações relacionados a educação, indicadores econômicos, instituições educacionais, } \\
\text { meio ambiente, saúde, transporte etc.; }\end{array}$ \\
\hline PSer 5 & Identificar o responsável ou gerenciador do site para possível contato ou responsabilização; \\
\hline PSer 7 & Disponibilizar um mecanismo para submissão, monitoramento e eliminação de queixas/denúncias públicas; \\
\hline PSer8 & Disponibilizar as notícias e informaçoses sobre políticas públicas \\
\hline PSer 9 & $\begin{array}{l}\text { Permitir o pagamento de impostos, taxas, contribuições de melhorias, multas etc.; essa prática deve permitir o } \\
\text { acesso a informações, preenchimento de guias, cálculo do tributo e possível multa e juros, inclusive, o } \\
\text { pagamento online; }\end{array}$ \\
\hline PSer 10 & $\begin{array}{l}\text { Permitir a consulta a dados cadastrais, débitos de veículos, emissão de guias para pagamentos de multas, } \\
\text { licenciamento, IPVA e seguro obrigatório, acesso à legislação e a programas de educação de trânsito; }\end{array}$ \\
\hline PSer11 & $\begin{array}{l}\text { Permitir a obtenção eletrônica de documentos tributários, como: consultas e certidões tributárias, nota fiscal e } \\
\text { eletrônica etc.; }\end{array}$ \\
\hline PSer 12 & Permitir o registro do cidadão e/ou empresa para serviços online; \\
\hline PSer13 & $\begin{array}{l}\text { Conceder licenças, registros ou permissões, como licença sanitária, licença; registro de cães e outros animais, } \\
\text { licença para abrir e fechar estabelecimentos, permissão para construção etc. }\end{array}$ \\
\hline PSer 14 & Permitir a compra de bilhetes para eventos etc.; \\
\hline PSer 15 & Possuir um mecanismo de compras eletrônicas mediante a realização de leilões online - pregão eletrônico - que \\
\hline
\end{tabular}




\begin{tabular}{|l|l|}
\hline & $\begin{array}{l}\text { consiste em um pregão via internet para negociações, automáticas e abertas, entre os órgãos do estado, os } \\
\text { compradores e os fornecedores do setor privado. }\end{array}$ \\
\hline PSer 16 & Publicar os editais de abertura de licitações e seus respectivos resultados \\
\hline
\end{tabular}

\begin{tabular}{|c|c|}
\hline & Práticas de participação cidadã \\
\hline PPC 1 & Possuir um boletim informative \\
\hline PPC 2 & Disponibilizar informações de governança \\
\hline PPC 3 & $\begin{array}{l}\text { Disponibilizar um e-mail para contato, com a descrição política adotada de resposta, começando com o tempo } \\
\text { e a data de recepção, o prazo estimado para a resposta, o que fazer se a resposta não for recebida e um cópia } \\
\text { de sua mensagem original; }\end{array}$ \\
\hline PPC 4 & $\begin{array}{l}\text { disponibilizar um quadro de anúncios, bate-papo, fórum de discussão, grupos de discussão, chats etc., para } \\
\text { discutir questões políticas, econômicas, sociais, com os gestores eleitos, órgãos específicos, especialistas etc., } \\
\text { facilitando o diálogo entre governo e cidadãos, com verdadeira possibilidade de participação. }\end{array}$ \\
\hline PPC 5 & $\begin{array}{l}\text { disponibilizar a agenda de reuniões ou calendário das discussões públicas, incluindo o tempo, lugar, agenda e } \\
\text { informações sobre os depoimentos dos cidadãos, participação, observação ou opções. }\end{array}$ \\
\hline PPC 6 & $\begin{array}{l}\text { Fazer pesquisas ou sondagens, breves ou mais detalhadas, de satisfação, opinião, manifestação de preferências } \\
\text { e sugestões, para verificar a percepção do cidadão quanto aos serviços prestados e à própria estrutura de } \\
\text { governança eletrônica; }\end{array}$ \\
\hline PPC 7 & Disponibilizar um canal específico para encaminhamento de denúncias. \\
\hline PPC 8 & $\begin{array}{l}\text { disponibilizar informações biográficas, e-mail, telefone, fotografia, endereço para contato com os gestores } \\
\text { eleitos e membros do governo; }\end{array}$ \\
\hline PPC 9 & Disponibilizar a estrutura e as funções do governo; \\
\hline PPC10 & $\begin{array}{l}\text { disponibilizar um link específico para "democracia" ou "participação cidadã" na página principal do seu site, } \\
\text { que o leva a uma seção especial, detalhando a finalidade e missão das unidades públicas, os decisores de alto } \\
\text { nível, permitindo ligações com a legislação, orçamento e outros detalhes de informação de accountability. }\end{array}$ \\
\hline
\end{tabular}

\begin{tabular}{|l|l|}
\hline N & \multicolumn{1}{c|}{ Práticas de privacidade e segurança } \\
\hline PPS1 & $\begin{array}{l}\text { Declarar a política de privacidade no site; descrevendo os tipos de informações recolhidas e as políticas de } \\
\text { utilização e partilha de informações recolhidas e as políticas de utilização e partilha das informações pessoais, } \\
\text { identificando os coletores das informações, disponível em todas as páginas que aceitam os dados, e com a data } \\
\text { em que a política de privacidade foi revisada; }\end{array}$ \\
\hline PPS2 & $\begin{array}{l}\text { Permitir diminuir a divulgação de informações pessoais, dispondo da possibilidade de entrar e sair do } \\
\text { fornecimento das informações; }\end{array}$ \\
\hline PPS3 & Permitir que o usuário revise os dados pessoais e conteste os registros de informações incompletas ou erradas; \\
\hline PPS4 & $\begin{array}{l}\text { Informar as práticas antes de qualquer informação pessoal ser coletada, evidenciando a entidade que está } \\
\text { obtendo a informação, o propósito do recolhimento, potenciais recebedores, natureza da informação, meios de } \\
\text { coleta, se as informações são voluntárias ou obrigatórias e consequência do não fornecimento; }\end{array}$ \\
\hline PPS 5 & $\begin{array}{l}\text { Limitar o acesso de dados e garantir que não será utilizado para fins não autorizados, utilizando senhas e } \\
\text { criptografia de dados sensíveis e procedimentos de auditoria; }\end{array}$ \\
\hline PPS 6 & $\begin{array}{l}\text { Disponibilizar um endereço de contato, telefone e/ou e-mail, específicos para denúncias, críticas, etc., sobre a } \\
\text { política de privacidade e segurança; }\end{array}$ \\
\hline PPS 7 & $\begin{array}{l}\text { Permitir o acesso a informações públicas por meio de uma área restrita que exija senha e/ou registro, como o } \\
\text { uso de assinatura digital para identificar os usuários. }\end{array}$ \\
\hline PPS 8 & $\begin{array}{l}\text { Permitir o acesso a informações não públicas para os servidores mediante uma área restrita que exija senha e/ou } \\
\text { registro }\end{array}$ \\
\hline
\end{tabular}

\begin{tabular}{|l|l|}
\hline & \multicolumn{1}{c|}{ Práticas de usabilidade e acessibilidade } \\
\hline PUA 2 & $\begin{array}{l}\text { Determinar o público-alvo do site, com canais personalizados para grupos específicos, como cidadãos, } \\
\text { empresas ou outros órgãos públicos; }\end{array}$ \\
\hline PUA 3 & $\begin{array}{l}\text { A barra de navegação deve ter os itens agrupados na área de navegação, termos claros utilizados para definir as } \\
\text { opções de navegação de categorias, ícones de navegação de reconhecimento imediato da classe de itens, links } \\
\text { identificados etc.; }\end{array}$ \\
\hline PUA 4 & Fornecer links clicáveis para a página inicial em todas as páginas, para os departamentos governamentais e para \\
\hline
\end{tabular}




\begin{tabular}{|l|l|}
\hline & sites relacionados fora do governo; \\
\hline PUA 5 & Disponibilizar na página inicial principal um mapa do site ou esboço de todos os sites; \\
\hline PUA 6 & $\begin{array}{l}\text { As páginas devem ser constituídas com cores padrão e consistentes, com a adequação de estilos de fonte, } \\
\text { formatação de texto, visibilidade dos elementos, critério para uso de logotipos etc.; }\end{array}$ \\
\hline PUA 7 & Os textos devem estar sublinhados indicando os links \\
\hline PUA 8 & disponibilizar a data da última atualização das páginas \\
\hline PUA 9 & $\begin{array}{l}\text { Fornecer um link para informações sobre o governo, com a possibilidade de contato, com endereço, telefone, } \\
\text { fax ou e-mail. }\end{array}$ \\
\hline PUA 10 & Disponibilizar versões alternativas de documentos longos, como arquivos em pdf ou doc. \\
\hline PUA 11 & $\begin{array}{l}\text { Permitir que os campos dos formulários sejam acessíveis por meio das teclas ou do cursor, identificando, } \\
\text { claramente, aqueles com procedimentos obrigatórios; fazendo com que a ordem das guias dos campos seja } \\
\text { lógica, ou seja, com o toque na tecla "tab" passa para o próximo campo; }\end{array}$ \\
\hline PUA 12 & Disponibilizar informações de como identificar e corrigir erros submetidos; \\
\hline PUA 13 & Dispor de um site de busca ou um link próprio site do governo; \\
\hline PUA 14 & $\begin{array}{l}\text { Dispor de seu próprio mecanismo de pesquisa, permitindo que pesquisas sejam feitas de forma específica, por } \\
\text { secretaria, em todo o site etc.; com recursos de pesquisas avançados, como a utilização de palavras, frases } \\
\text { exatas, combinação etc.; com capacidade para classificar os resultados da pesquisa por relevância ou outros } \\
\text { critérios; }\end{array}$ \\
\hline PUA 15 & Disponibilizar um mecanismo de acesso aos portadores de necessidades especiais \\
\hline PUA 16 & Disponibilizar o conteúdo do site em mais de um idioma; \\
\hline PUA 17 & Apresentar os textos escritos com fontes e cores adequadas \\
\hline PUA 18 & Disponibilizar os conteúdos de áudio com transcrições escritas e/ou legendas; \\
\hline PUA 19 & Permitir o acesso ao site e seus conteúdos por meio do teclado do computador \\
\hline
\end{tabular}

